\title{
Cavernous hemangioma of transverse colon : unexpected result after polypectomy
}

\section{Abstract}

A cavernous hemangioma of the transverse colon is a rare vascular malformation but is clinically important because of the possibility of massive bleeding.
Volume 7 Issue 2 - 2017

\author{
Hüseyin Sancar Bozkurt,' Banu Kozat Kara, ${ }^{2}$ \\ Ayșe Polat ${ }^{3}$ \\ 'Department of Gastroenterology, Medical Park Private Tarsus \\ Hospital,Turkey \\ ${ }^{2}$ Department of Gastroenterology, Adana Numune Training and \\ Research Hospital,Turkey \\ ${ }^{3}$ Department of Pathology, Mersin Private Pathology and \\ Cytology Laboratuary, Turkey
}

Correspondence: Hüseyin Sancar Bozkurt, Private Tarsus Medical Park Hospital, Gastroenterology, Turkey, Tel 9.05054482291,Email sancarb79@gmail.com

Received: May 09, 2017 | Published: June 28, 2017

\section{Introduction}

Hemangiomas of the large intestine are relatively uncommon benign tumors which can occur anywhere in the gastrointestinal tract. ${ }^{1}$ The symptoms of hemangiomas depend on the localization of the primary tumor. Nevertheless the most common primary manifestation is spontaneous bleeding. ${ }^{2,3}$ We report a case of a cavernous hemangioma mimicking atypic polipoid lession in the transverse colon which was removed successfully using snare polypectomy.

\section{Case report}

A 67-year-old woman was referred to hospital because of iron deffiency anemia.Upper endoscopic invastigation was normal. Colonoscopy revealed a polypoid lesion with a nodular surface in the transverse colon (Figure 1). The atypical polypoid lession was removed succesfully using snare polypectomy (Figure 2). The bleeding occurred during polypectomy and as there weren't any clips, adrenalin injection was used to control bleeding (Figure 3). The bleeding stopped and the patient was discharged. After 3 months we performed a repeat colonoscopy. The lesion had disappeared. There were no early and delayed complications. The pathology report was consistent with colonic cavernous hemangioma (Figure 4).

\section{Discussion}

Hemangiomas are uncommon hamartomatous lesions that originate from the embryonic sequestrations of mesodermal tissue and can be found in any organ. ${ }^{4}$ Hemangiomas are classified histologically and named according to their major components. There are three principal types: capillary, cavernous and mixed. The cavernous variant is the most common. ${ }^{4}$ The endoscopic findings of hemangiomas of the colon vary. Grossly, hemangiomas appear as soft, compressible bluish or deep red submucosal lesions, with dilated, engorged veins in the colon wall. However, they can be difficult to diagnose in some cases, especially if the hemangioma has an unusual color or is covered. A histological diagnosis before treatment may be difficult because of the risk of uncontrollable bleeding following a biopsy. ${ }^{5}$ In our case as we thought it was a polyp and did not suspect a hemangioma we did not perform an advanced evaluation such as endosonography and treated it like a polyp. After the biopsy report we noticed that it is a cavernous hemangioma. It is an unexpected result and we could not find a reported case in the literature. Here we report a case of a cavernous hemangioma mimicking as an atypic polipoid lession in the transverse colon which was removed successfully using snare polypectomy.

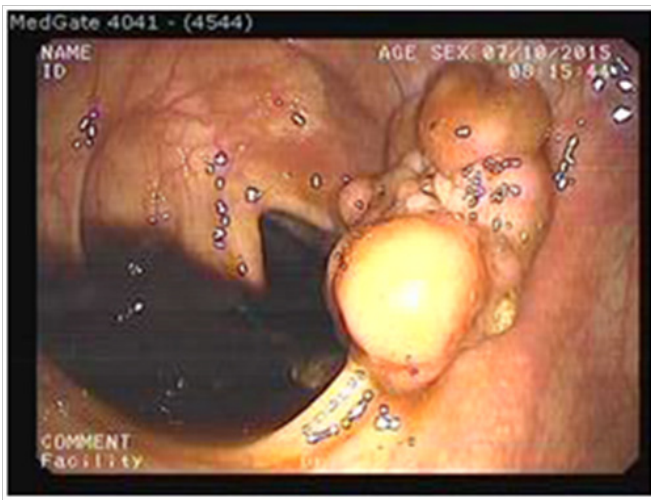

Figure I Polipoid lession in transvers colon.

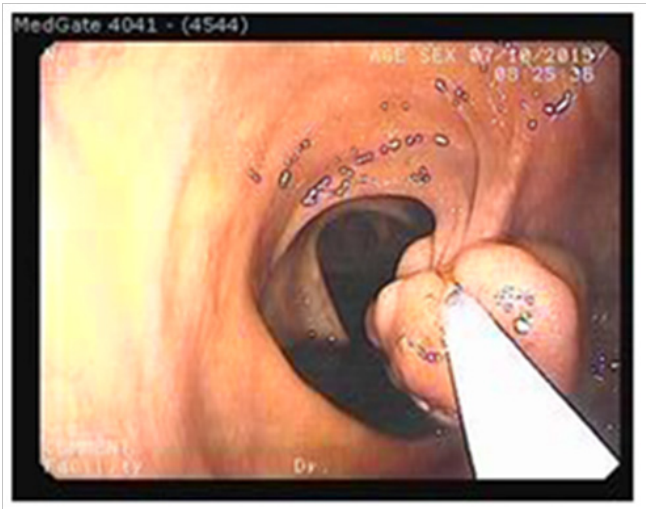

Figure 2 Using snare polypectomy. 


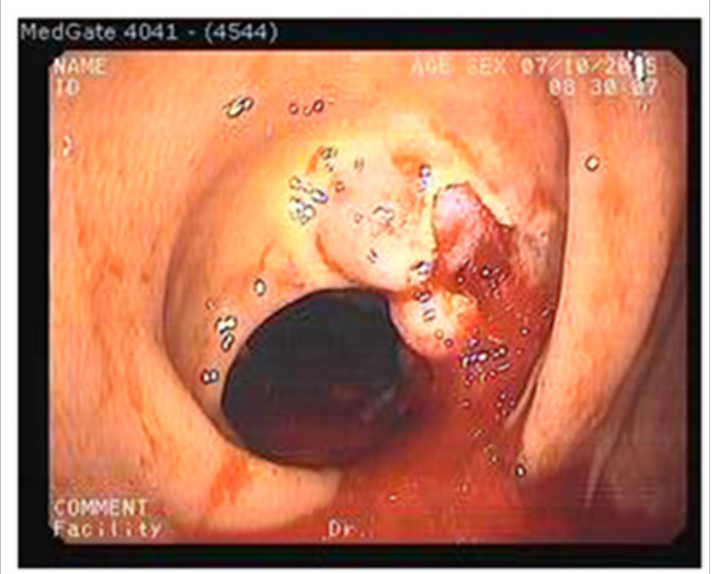

Figure 3 The bleeding occurred during polypectomy.

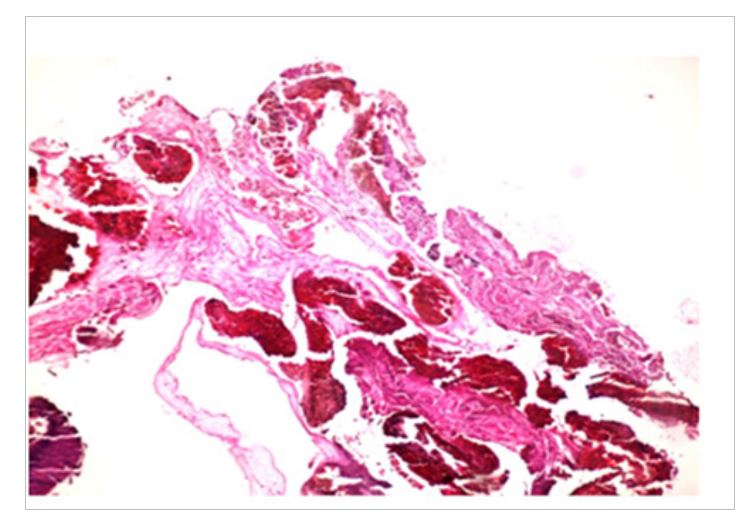

Figure $4 \mathrm{HE}$ staining of the hemangioma. Histological section showing large, dilated, blood-filled vessels lined by flattened endothelium $(\mathrm{HE}, \times 100)$.

\section{Acknowledgments}

None.

\section{Conflicts of interest}

The authors declare there are no conflicts of interest related to the article.

\section{Funding \\ None.}

\section{References}

1. Pontecorvo C, Lombardi S, Mottola L, et al. Hemangiomas of the large bowel. Report of a case. Dis Colon Rectum. 1983;26(12):818-820.

2. Enziger FM, Weiss SW. Soft Tissue Tumors. 3rd edn, St Louis, MosbyYearbook, MO, USA. 1995.

3. Levy AD, Abbott RM, Rohrmann CA Jr, et al. Gastrointestinal hemangiomas: imaging findings with pathologic correlation in pediatric and adult patient. AJR Am J Roentgenol. 2001;177(5):1073-1081.

4. Schwartz GD, Barkin JS. Small bowel tumors. Gastrointest Endosc Clin NAm. 2006;16(2):267-275.

5. Hasegawa K, Lee WY, Noguchi T, et al. Colonoscopic removal of hemangiomas. Dis Colon Rectum. 1981;24(2):85-89. 